\title{
Fragmentation of biomass-templated CaO-based pellets
}

María Erans ${ }^{\mathrm{a}}$, Francesca Cerciello ${ }^{\mathrm{b}}$, Antonio Coppola ${ }^{\mathrm{b}}$, Osvalda Senneca ${ }^{\mathrm{b}}$, Fabrizio Scala ${ }^{b}$, Vasilije Manovic ${ }^{a}$ and Edward J. Anthony ${ }^{a \star}$

${ }^{a}$ Combustion and CCS Centre, Cranfield University, Bedford, Bedfordshire, MK43 OAL, UK

${ }^{b}$ Dipartimento di Ingegneria Chimica, Università degli Studi di Napoli Federico II, Istituto di Ricerche sulla Combustione (C.N.R.), P.le Tecchio 80, Naples, Italy

Corresponding author*: Professor Edward J. Anthony

Combustion and CCS Centre

Cranfield University

Bedford, Bedfordshire, MK43 OAL, UK

+44 (0) 1234750111 ext. 2823

b.j.anthony@cranfield.ac.uk 


\section{Fragmentation of biomass-templated CaO-based pellets}

María Erans ${ }^{a}$, Francesca Cerciello ${ }^{b}$, Antonio Coppola ${ }^{b}$, Osvalda Senneca ${ }^{b}$, Fabrizio Scala ${ }^{b}$, Vasilije Manovic and Edward J. Anthonya*

a Combustion and CCS Centre, Cranfield University, Bedford, Bedfordshire, MK43

OAL, UK

${ }^{\text {b }}$ Dipartimento di Ingegneria Chimica, Università degli Studi di Napoli Federico II, Istituto di Ricerche sulla Combustione (C.N.R.), P.le Tecchio 80, Naples, Italy b.j.anthony@cranfield.ac.uk / +44 (0) 1234750111 ext. 2823

\section{Abstract}

The use of biomass-templating materials with a cheap production method as an enhanced sorbent for $\mathrm{CO}_{2}$ uptake has been proposed recently. However, the attrition and fragmentation behaviour of this type of material, which is a vital parameter for calcium looping sorbents, has not yet been investigated in detail. In this work the attrition and fragmentation behaviour of biomass-templated sorbents is investigated. Three types of materials were prepared using a mechanical pelletiser: 1. lime and cement (LC); 2. lime and flour (LF); and 3. lime, cement and flour (LCF). These samples were heat treated in a pressurised heated strip reactor (PHSR) and in a bubbling fluidised bed (BFB) and changes in particle size distribution were measured to assess fragmentation. Results indicated that the addition of biomass enhances the propensity to undergo fragmentation. Upon heat treatment in the PHSR the particle size of LC was not modified significantly; on the contrary the mean particle diameter of LF decreased from $520 \mu \mathrm{m}$ to $116 \mu \mathrm{m}$ and that of LCF from $524 \mu \mathrm{m}$ to $290 \mu \mathrm{m}$. Fragmentation tests in the BFB confirmed the trend: $67 \%$ of the particles of LF fragmented, against $53 \%$ of LCF and $18 \%$ of LC samples. The addition of biomass to the LC samples partially counteracts this performance degradation with respect to attrition. However, calcium aluminate pellets (LC) showed the lowest rate of fragmentation amongst all of the samples tested.

Keywords: Calcium looping, pellets, biomass-templating, fragmentation 


\section{Introduction}

Calcium looping $(\mathrm{CaL})$ is a second-generation carbon capture technology, which uses a lime sorbent in dual fluidised-bed reactors; this technology depends on the following reversible exothermic calcium oxide carbonation reaction:

$$
\mathrm{CaO}(s)+\mathrm{CO}_{2}(g) \leftrightarrow \mathrm{CaCO}_{3}(s)
$$

The typical reactor set-up consists of two interconnected fluidised-bed reactors. In the first reactor (the carbonator) the $\mathrm{CaO}$-based sorbent captures $\mathrm{CO}_{2}$ from power plant flue gas; this reaction occurs at a practical rate at $650-700^{\circ} \mathrm{C}$ [1-3]. The carbonated sorbent is then transferred to the second reactor (the calciner) where $\mathrm{CO}_{2}$ is released at high temperatures $\left(850-950^{\circ} \mathrm{C}\right)$. The regenerated material is then returned to the carbonator for the next cycle. However, there are several challenges with $\mathrm{CaO}$-based sorbent whose $\mathrm{CO}_{2}$ uptake decreases with increasing number of carbonation/calcination cycles. This decline in activity is mainly due to sintering during calcination because of the high temperatures necessary for calcination [4-8]. The $\mathrm{CO}_{2}$ capture capacity of the fresh sorbent drops quickly during the initial cycles until an asymptotic value is achieved after about 20 or 30 cycles, which then remains almost constant over subsequent cycles and adopts typical values of about $0.08 \mathrm{~g}$ $\mathrm{CO}_{2} / \mathrm{g}$ sorbent in the case of limestone [9]. This reduction in performance can be partially compensated by increasing the $\mathrm{Ca} / \mathrm{C}$ ratio in the reactor (by increasing the purge of spent sorbent and the make-up ratio) or by modifying the properties of the particles [10]. However, this deactivation can also be caused by sulphation or ash fouling [11].

Natural sorbents (limestone and dolomite) are attractive due to their low cost, ready availability and, in the case of limestones, the potential suitability of the CaL purge material for the cement industry $[12,13]$. However, significant research efforts are being made to modify limestone sorbents or create new synthetic sorbents using techniques such as sol-gel combustion [14-18], organic acid modifications [19-23], co-precipitation [24, 25] and granulation [26-32]. Such materials exhibited higher $\mathrm{CO}_{2}$ uptake, in general, when compared to natural lime-based sorbents. However, the cost of these sorbents increases due to such complex production procedures and the cost of the additives and may become prohibitively expensive.

One of the methods proposed to improve the performance of calcium looping sorbents was biomass templating [30]. Such biomass is potentially a cheap material for increasing the porosity of pelletised sorbents. Ridha et al. [30] observed that the capture capacity was $0.41 \mathrm{~g} \mathrm{CO}_{2} / \mathrm{g}$ sorbent after 20 cycles in the presence of $15 \%$ steam for sorbents with $10 \%$ of powdered leaves incorporated into the sorbent. This was an increase of $33.3 \%$ when compared to the untemplated materials after both samples underwent 20 cycles. The use of flour as a biomass-templating material has been studied by Erans et al. [32]. These materials were tested in both a thermogravimetric analyser (TGA) and a bubbling fluidised bed (BFB), and the synthesised materials were shown to exhibit better performance than natural 
limestone. However, under BFB conditions the templated materials demonstrated higher rates of fragmentation and attrition compared to calcium aluminate pellets without the addition of biomass.

Attrition of lime based sorbents has been extensively investigated in previous studies [33-36]. There are several attrition/fragmentation mechanisms: primary fragmentation, which occurs when the sorbent is injected into the reactor due to thermal stresses and overpressures caused by $\mathrm{CO}_{2}$ release from the calcination reaction; secondary fragmentation, which occurs due to mechanical stresses from collisions between particles and bed internals; and attrition by abrasion, which is also caused by mechanical stresses but generates finer particles when compared to secondary fragmentation [37]. It has also been reported that the attrition rate was higher during the initial cycles and then subsequently decreased [38, 39].

Previous results have shown the beneficial effect of biomass addition for the $\mathrm{CO}_{2}$ uptake, as well as demonstrating the enhanced porous structure of the templated samples. However, there are discrepancies between TGA results and BFB results; and these differences are believed to be due to attrition and fragmentation. This work explores the effect of biomass templating in calcium aluminate pellets with regard to fragmentation. Three different types of materials: one with the addition of calcium aluminate cement (LC), another with flour addition (LF) and one with both (LCF) have been tested in two different types of reactors; namely a pressurised heated strip reactor (PHSR) and bubbling fluidised bed under different conditions.

\section{Experimental}

\subsection{Materials}

Longcal limestone from the UK was used as a lime precursor. Commercial calcium aluminate cement, CA-14, manufactured by Almantis, was used as a binder in the pelletisation process and as a source of $\mathrm{Al}_{2} \mathrm{O}_{3}$. Commercial flour was used as the biomass templating material.

\subsection{Pellet preparation procedure}

Three types of materials were produced: (i) 10\% calcium aluminate cement and $90 \%$ calcined limestone (LC); (ii) $10 \%$ flour and $90 \%$ calcined limestone (LF); and (iii) $10 \%$ flour, $10 \%$ calcium aluminate cement and $80 \%$ calcined limestone (LCF). The particles were prepared introducing the desired proportional quantities in $1 \mathrm{~kg}$ batches into a pelletiser vessel $(4 \mathrm{~L})$. The mixing took place inside the vessel by means of a chopper and agitator under a continuous water spray. A more detailed explanation of this procedure can be found elsewhere [27]. After pelletisation of the samples, the particles were sieved to different particle sizes. The material was air dried for $24 \mathrm{~h}$ before storage. The weight percentage of materials used in each sample can be found in Table1. 


\begin{tabular}{llll}
\hline Sample & Lime $(w t \%)$ & $\begin{array}{l}\text { Calcium aluminate } \\
\text { cement }(w t \%)\end{array}$ & Flour $(w t \%)$ \\
\hline LC & 90 & 10 & 0 \\
LF & 90 & 0 & 10 \\
LCF & 80 & 10 & 10 \\
\hline
\end{tabular}

\subsection{Fragmentation experiments}

For the fragmentation experiments two experimental systems have been used: a pressurised heated strip reactor and a bubbling fluidised bed.

The apparatus used for the first round of tests (the PHSR) achieves a heating rate of $4000^{\circ} \mathrm{C} / \mathrm{s}$. Batches of particles of $500-710 \mu \mathrm{m}$ are placed on the strip and heated up by physical contact with the strip and by thermal radiation from the semi-spherical cover of the reactor. Further details of this reactor are available elsewhere [40]. Tests have been carried out at 1 bar and $950^{\circ} \mathrm{C}$ in pure $\mathrm{N}_{2}$. The final temperature was held for $30 \mathrm{~s}$ in all experiments. After the test, particles were recovered and the experiments were repeated on fresh particles numerous times ( 10-15 times) in order to collect a sufficiently large amount of material to perform further particle size analyses.

Further fragmentation tests were carried out in a lab-scale BFB in order to reproduce conditions typical of the first calcinations step. The BFB had a $40 \mathrm{~mm} I D$, and was operated at atmospheric pressure and heated to the desired temperature by means of an external electric furnace. Calcination of the particles was performed under two conditions: $100 \%$ vol air and $70 \%$ vol $\mathrm{CO}_{2} / 30 \%$ vol air. The calcination time for all the experiments was $20 \mathrm{~min}$ to ensure complete calcination. These tests were repeated for two different particle size ranges: 500-710 $\mu \mathrm{m}$ and 250-500 $\mu \mathrm{m}$.

For the BFB tests, $20 \mathrm{~g}$ of sorbent was diluted in $150 \mathrm{~g}$ of silica (particle size distribution of $850-1000 \mu \mathrm{m}$ ) sand to avoid excessive decrease of temperature in the bed during calcination, due to the endothermic reaction of the sorbent. All the experiments were performed isothermally at $900^{\circ} \mathrm{C}$.

It is important to note that in the present work the focus is on the first calcination step due to the fact that the highest attrition rate occurs in the first cycle rather than in the following cycles. Therefore, this first calcination is considered to provide a good indication of sorbent attrition behaviour [41, 42].

\subsection{Sample characterisation}

The biomass-containing materials (LF and LCF) were analysed by TGA in a Netzsch STA409 CD apparatus in order to investigate the effect of biomass pyrolysis and combustion throughout calcination of the templated sorbents. Two different types of tests have been carried out, namely, pyrolysis-calcination and combustion-calcination tests.

In pyrolysis-calcination tests the sample was dried in argon at $110^{\circ} \mathrm{C}$, and then the temperature was taken to $900^{\circ} \mathrm{C}$ in argon with a ramp rate of $5^{\circ} \mathrm{C} / \mathrm{min}$. At $900^{\circ} \mathrm{C}$ the 
gas was switched from argon to air and the samples were held at isothermal conditions for $60 \mathrm{~min}$, before being cooled at a rate of $20^{\circ} \mathrm{C} / \mathrm{min}$.

In combustion-calcination tests the sample was exposed to air flow from the very beginning. It was dried at $110^{\circ} \mathrm{C}$ and then taken to $370^{\circ} \mathrm{C}$ with the heating rate of 10 ${ }^{\circ} \mathrm{C} / \mathrm{min}$. An isothermal step of $10 \mathrm{~min}$ in air was performed at $370^{\circ} \mathrm{C}$ to allow combustion of biomass. Finally, the sample was heated to $900^{\circ} \mathrm{C}$ at a similar heating rate and kept at this temperature for $10 \mathrm{~min}$ to allow calcination.

Approximately $30 \mathrm{mg}$ of sample were used for each experiment, with a gas flow rate of $200 \mathrm{~mL} / \mathrm{min}$. In the case of LCF, additional tests were performed for the following particle size ranges: $710-500 \mu \mathrm{m}$ and $250-500 \mu \mathrm{m}$ in order to investigate the effect of particle size.

Sample morphology was observed with a FEI Inspect S Scanning Electron Microscope (SEM) with $20 \mathrm{kV}$ of accelerating voltage under high vacuum. The calcined samples were put in the SEM chamber together with the ceramic pan. Before the analysis, the samples were coated with gold to avoid excessive charging. The porosimetry was studied using an AutoPore IV 9500 with mercury intrusion.

The particle size distribution was measured using the Mastersizer 2000 (Malvern, UK) and acetone was used as a carrier liquid. For X-ray diffraction analysis (XRD) a D2 Phaser (Bruker, Germany) apparatus with $\mathrm{Cu}$ Ka radiation (30 kV, $10 \mathrm{~mA}$ ) was used. Scattered X-ray intensities were recorded between $2 \theta=5$ and $75^{\circ}$ with a scan velocity of $0.052 \theta \mathrm{s}^{-1}$.

\section{Results and discussion}

\subsection{Sorbent characterisation}

Figures 1 and 2 report the mass loss profiles obtained during TGA experiments of pyrolysis-calcination and combustion-calcination.

In the case of LF a first stage of mass loss is observed between $350-450^{\circ} \mathrm{C}$ followed by a second stage of mass loss between $650-700^{\circ} \mathrm{C}$, which can be associated with flour pyrolysis and sorbent calcination, respectively. Interestingly, the mass appears to be higher under pyrolysis conditions than under combustion, possibly due to the concurrent uptake of $\mathrm{H}_{2} \mathrm{O} / \mathrm{CO}_{2}$ from air. In the combustion-calcination test a more noticeable uptake of $\mathrm{CO}_{2}$ is evident above $450^{\circ} \mathrm{C}$. The release of $\mathrm{CO}_{2}$ at still higher temperature supports the similar value of value of $60 \%$, which is observed for the final residue after both pyrolysis-calcination and combustion-calcination of the flour templated samples.

In the case of LCF two stages of mass loss are observed associated with flour pyrolysis and sorbent calcination. The effect of $\mathrm{CO}_{2}$ uptake in the combustioncalcination test is less striking for LCF than for LF, due to the smaller percentage of lime in LCF. 
The fact that the final residue of the combustion-calcination tests exceeds that of the pyrolysis-calcination tests by $5 \%$ suggests that some structural changes in the cement phase might have occurred in air.

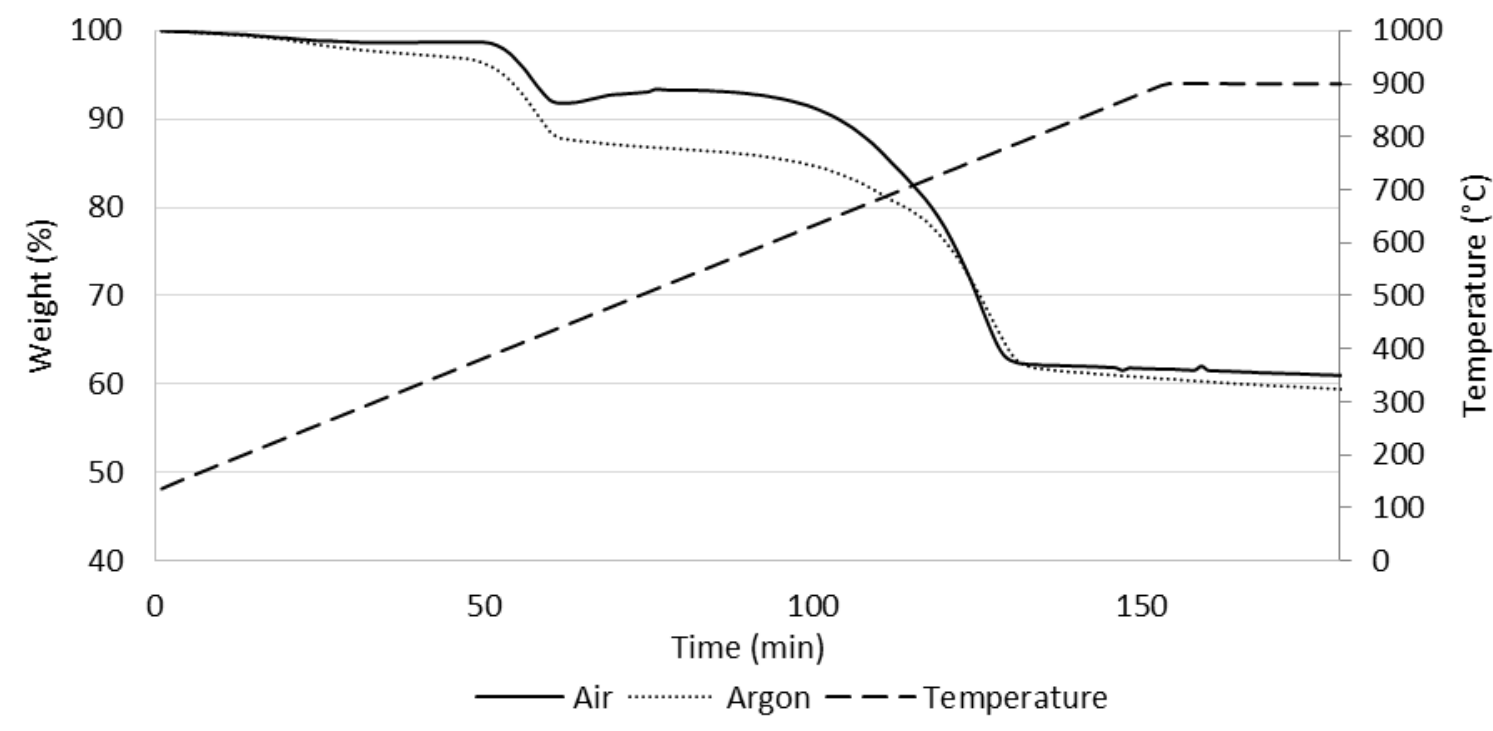

Figure 1: TG (\%) and temperature of tests in air and argon of LF

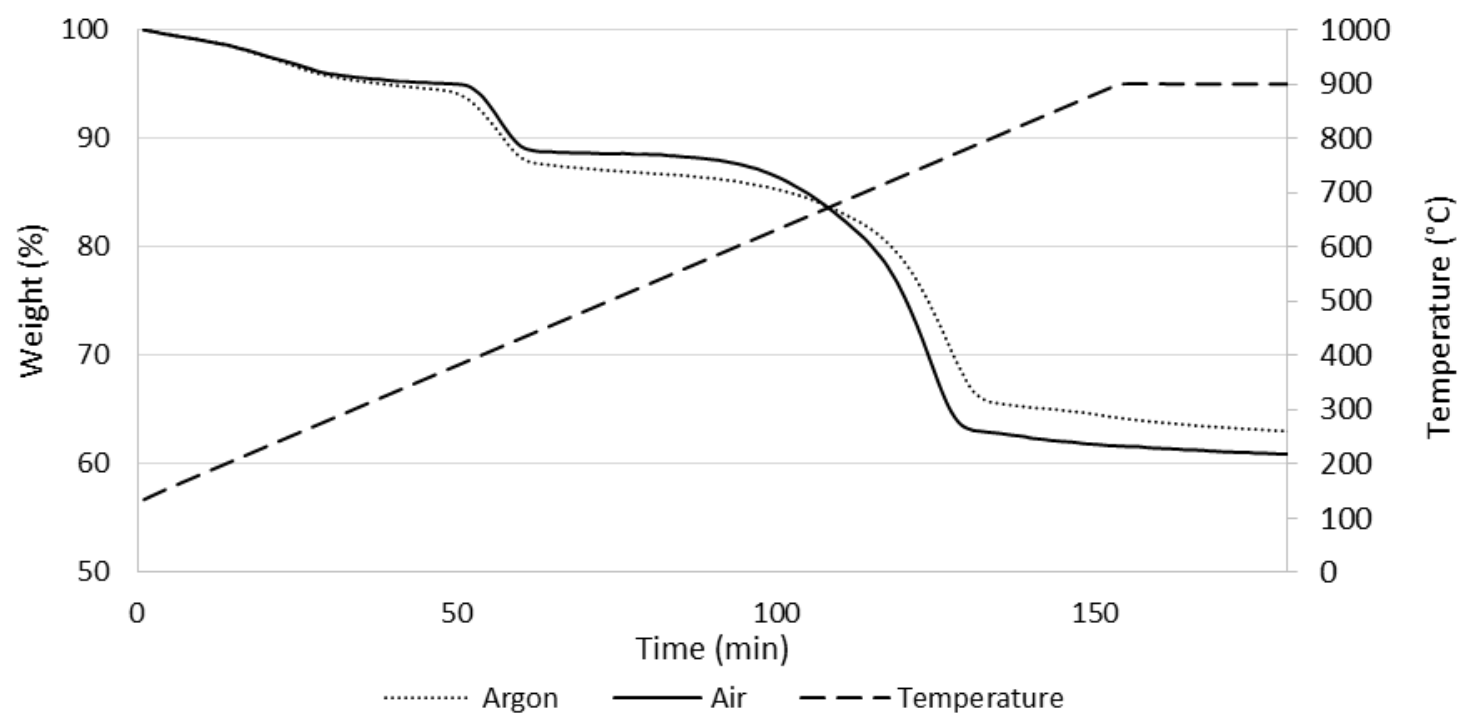

Figure 2: TG (\%) and temperature of tests in air and argon of LCF

Figures 3, 4 and 5 show typical SEM images of LC, LF and LCF, respectively, after calcination. There are clear differences in structure: it is evident that the LC has a more compact structure, whilst LF has a more porous surface, as can be seen in Figure 4, due to the addition of flour, which creates mesopores in the structure. LCF displays a mixture of both structures, and it is definitely denser than LF; however, it has smaller pores and a more porous structure than LC. 

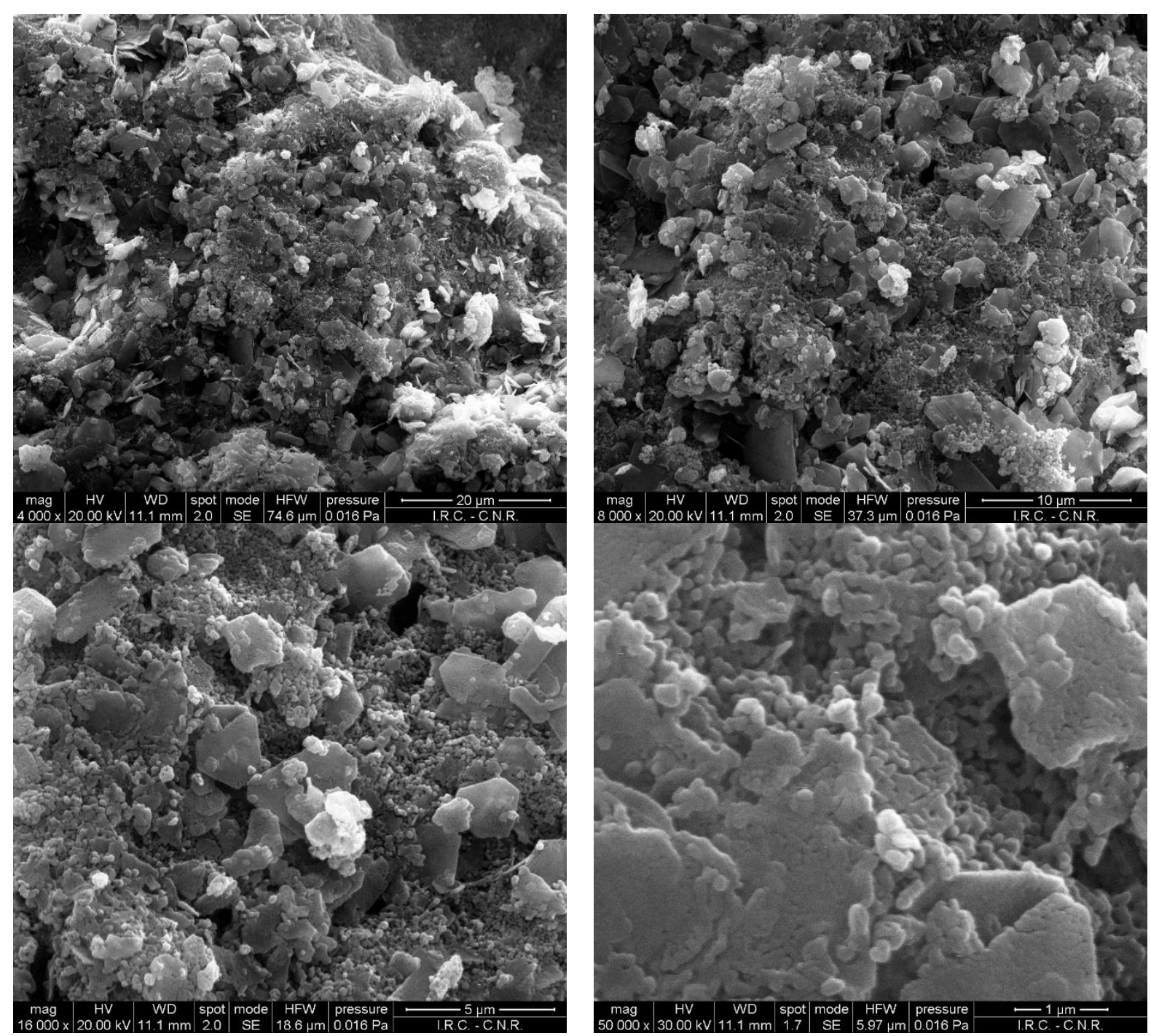

\section{Figure 3: SEM images of calcined LC at $20 \mathrm{kV}$ and different magnifications}
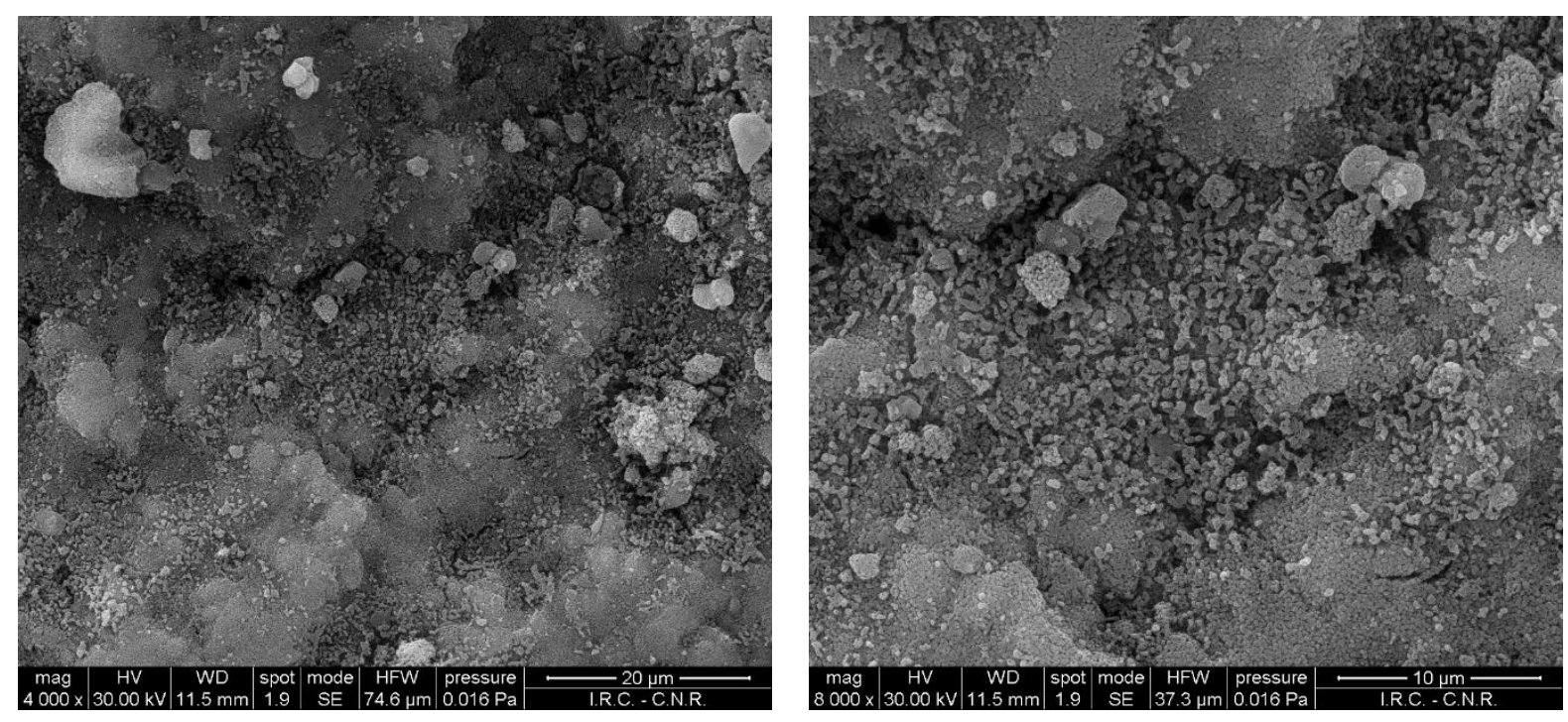

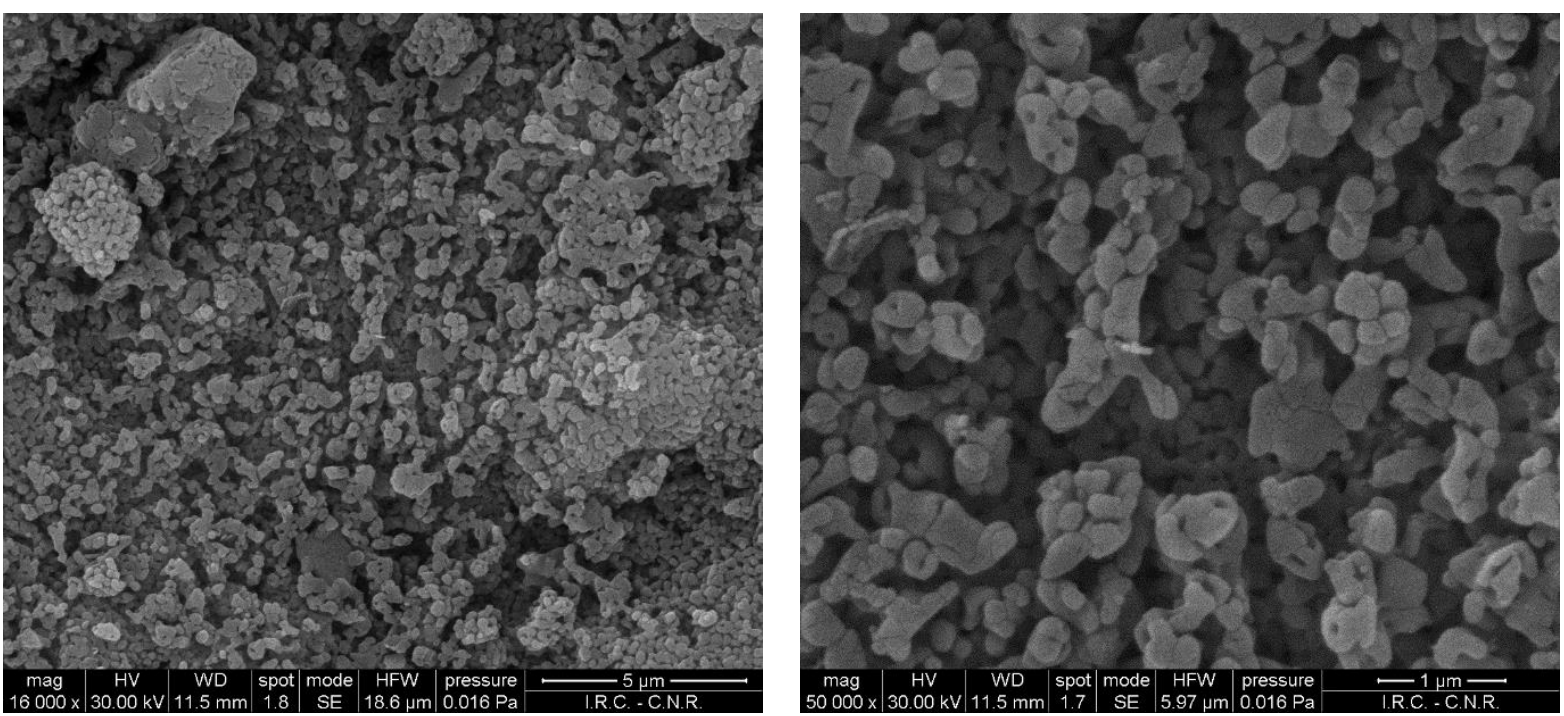

Figure 4: SEM images of calcined LF at $20 \mathrm{kV}$ and different magnifications
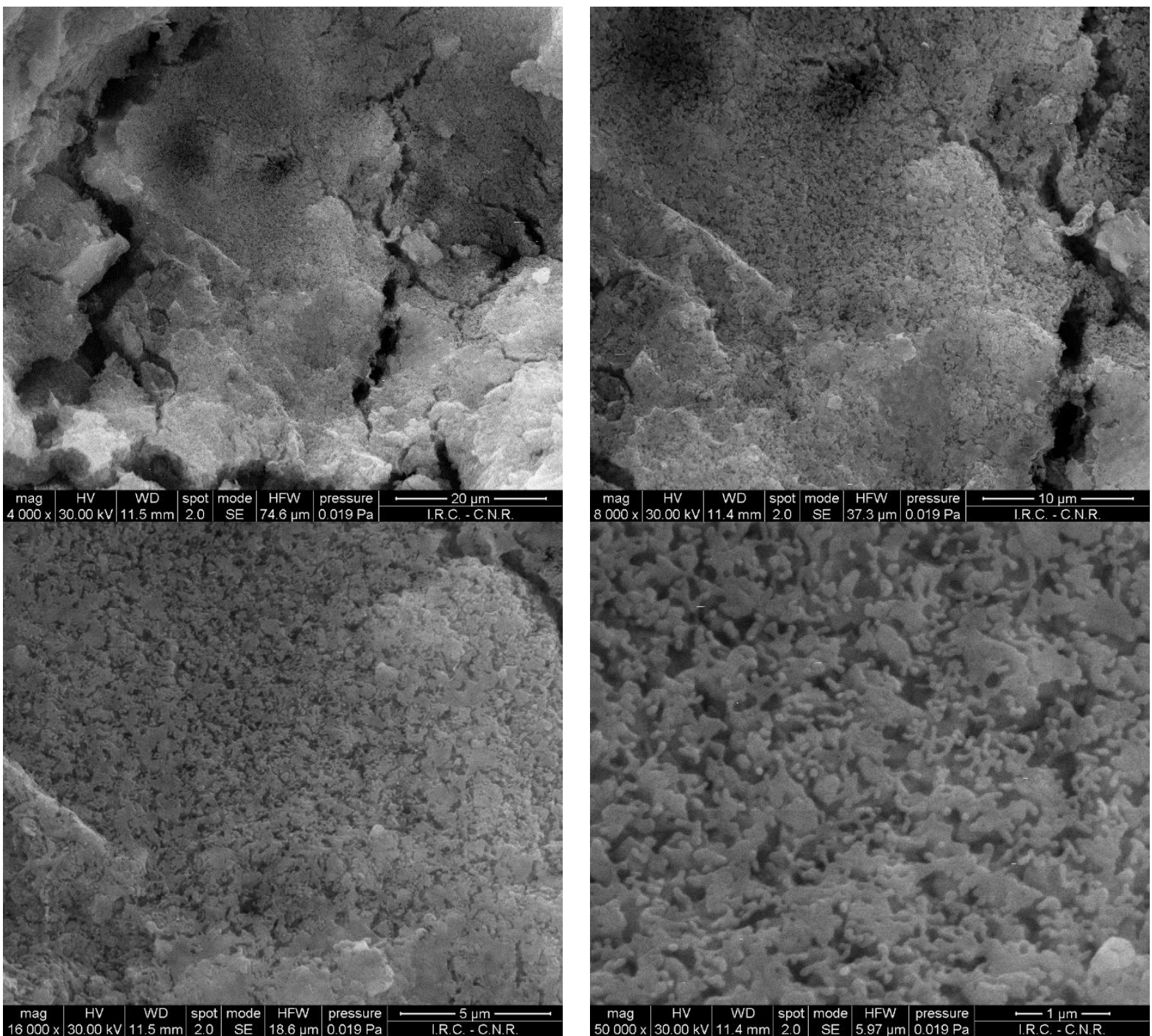

Figure 5: SEM images of calcined LCF at $20 \mathrm{kV}$ and different magnifications

170 In Figure 6 the mercury intrusion pore volume $(\mathrm{dV} / \mathrm{dD})$ is shown. From these data, it 171 can be inferred that there is a difference in the pore size distribution. In LC, there is a 172 greater amount of larger pores (around $100 \mathrm{~nm}$ ) than in LF and LCF and this was 
expected due to the addition of biomass; this addition creates smaller pores, as has been mentioned above. However, it can be seen that the total pore surface area is lower in the sample with biomass-only templating (LF) with a total pore area of 13.2 $\mathrm{m}^{2} / \mathrm{g}$ compared to $15.0 \mathrm{~m}^{2} / \mathrm{g}$ (LC). Further, this seems to be mitigated when adding cement, as the pore area is increased to $17.12 \mathrm{~m}^{2} / \mathrm{g}$ (LCF). This increase in area is believed to be related to the mesoporous $\mathrm{Al}_{2} \mathrm{O}_{3}$ phase formed by the addition of the calcium aluminate cement in the pelletisation process [43].

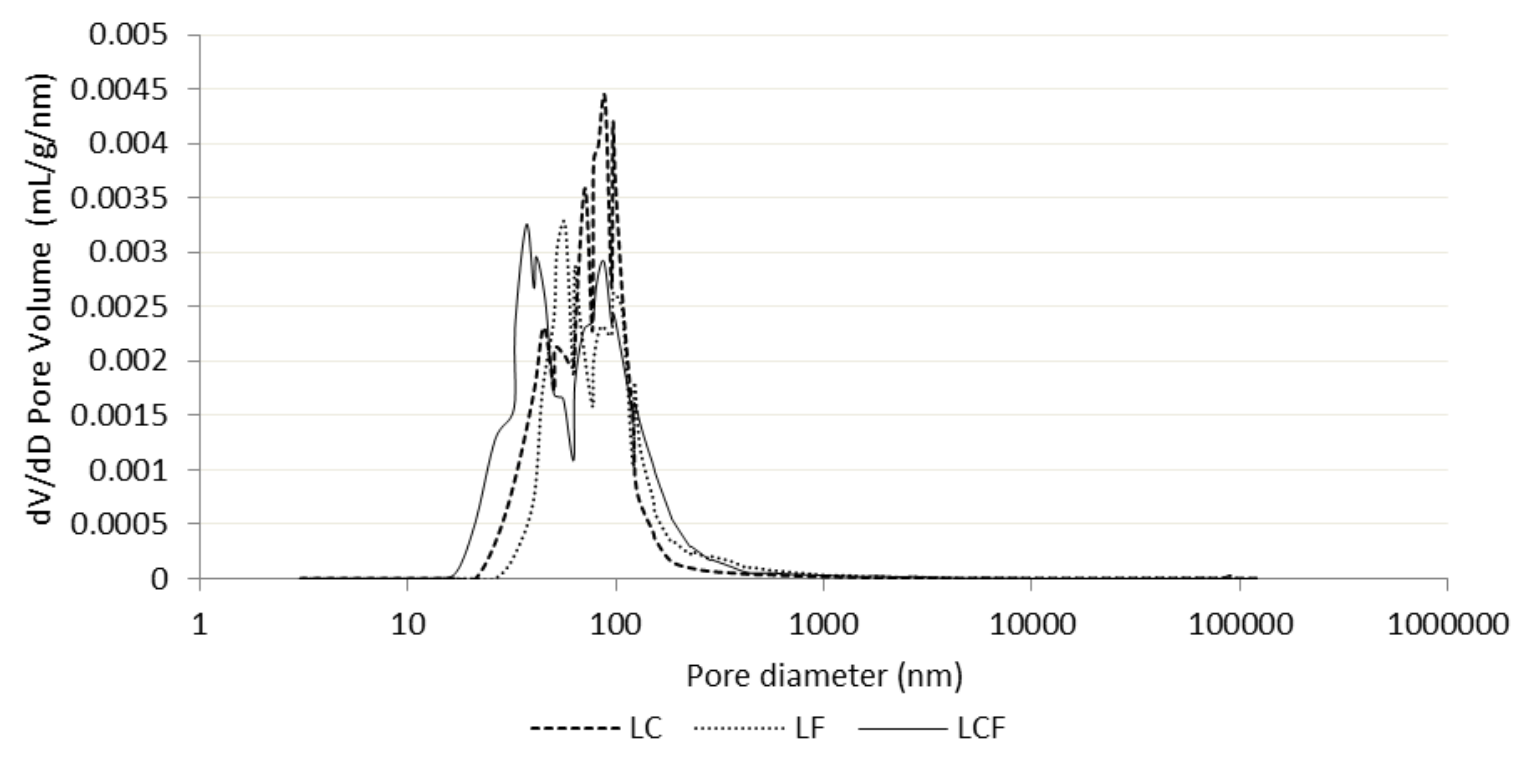

Figure 6: $\mathrm{dV} / \mathrm{dD}$ pore volume vs pore diameter for calcined LC, LF and LCF

XRD analysis of the samples was also carried out for LC, LF and LCF. The results of this analysis can be seen in Figure 7. The differences in composition of the samples are mainly in the mayenite $\left(\mathrm{Ca}_{12} \mathrm{Al}_{14} \mathrm{O}_{33}\right)$ phase that forms from the reaction between calcium aluminate cement and lime in the production process. These outcomes have been well documented in earlier investigations [44, 45]. 


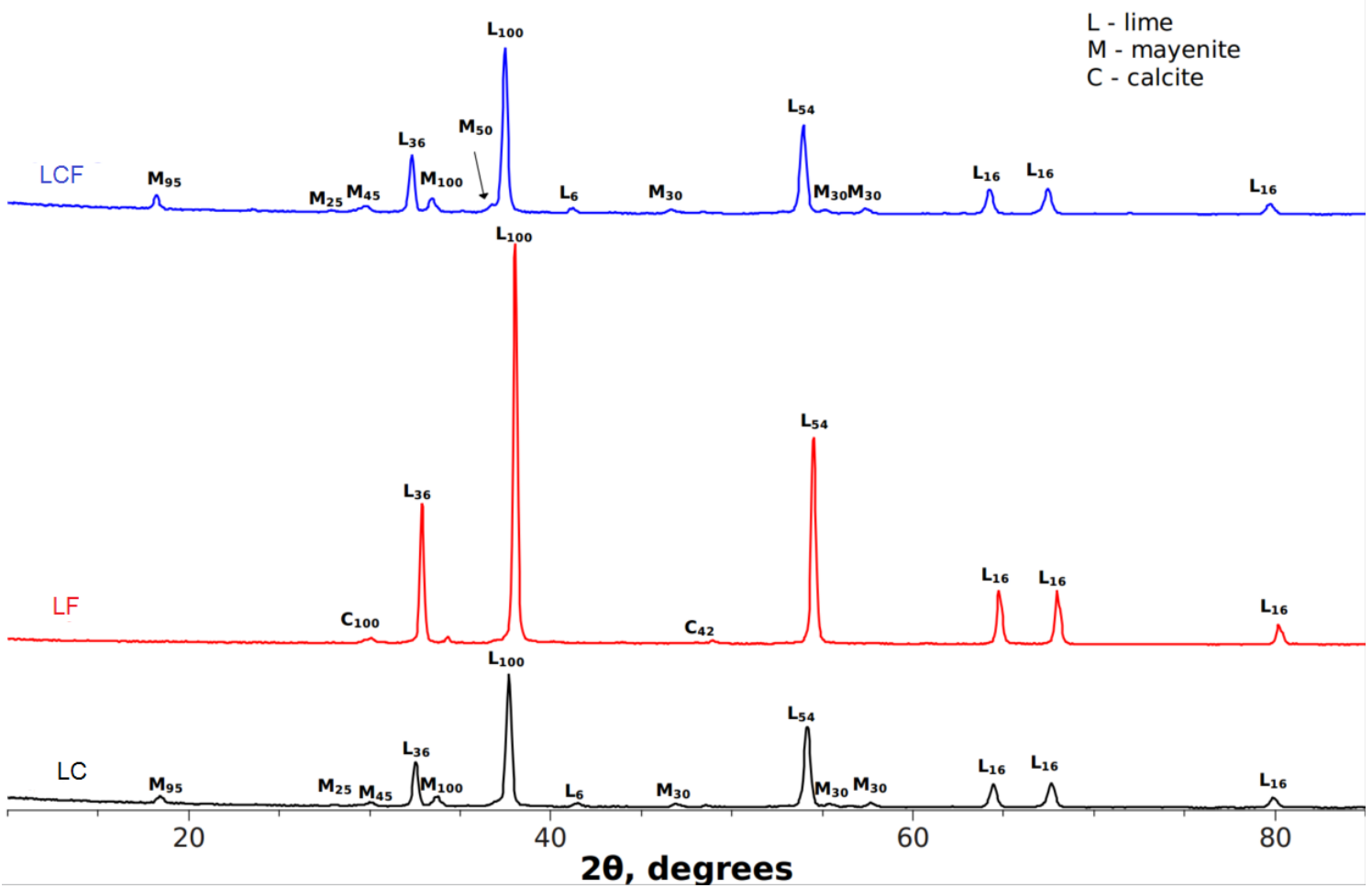

188 Figure 7: XRD of calcined LC, LF and LCF

\subsection{Fragmentation tests}

\subsubsection{PHSR tests}

191 The PHSR tests were performed repeatedly with raw samples until enough material was collected to analyse particle size distribution (PSD). In Figure 8, the PSD for LC is shown, comparing the raw material with the material after injection into the reactor, simulating the conditions at the entrance of the calciner. It can be seen that the PSDs are similar. However, it should be noted that the fine particles present in the raw sample probably became finer still, and could not be recovered after the PHSR experiment.. Nonetheless, the mean diameter is almost equal in both the raw material and the treated sample. 


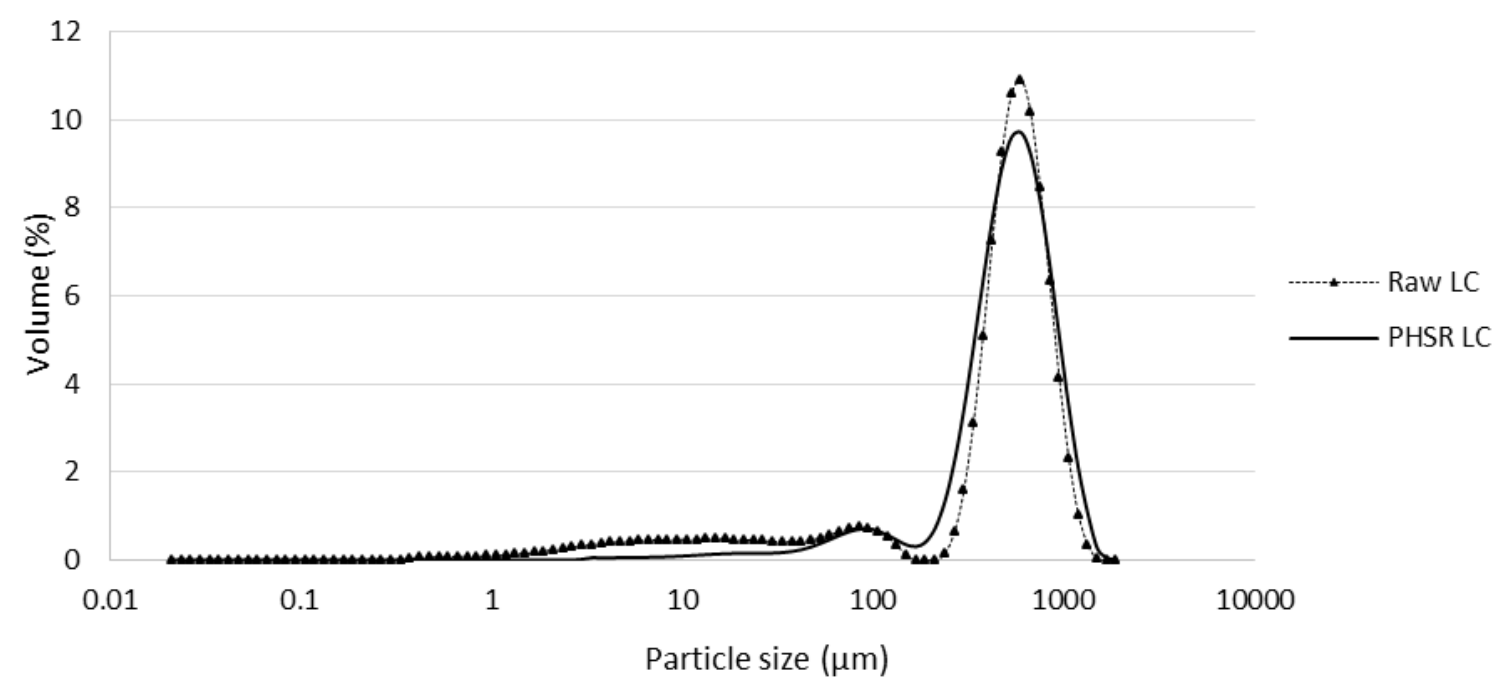

Figure 8: Particle size distribution of LC before and after the PHSR tests

The same distributions are shown for LF and LCF in Figures 9 and 10, respectively. For LF the difference in the particle size distribution before and after the fragmentation experiment is quite significant, with major fragmentation occurring when the particles are treated at $950^{\circ} \mathrm{C}$, and the mean diameter decreases substantially from $520 \mu \mathrm{m}$ to $116 \mu \mathrm{m}$. However, for LCF the change is less pronounced, although there is some fragmentation occurring when compared to LC; the change in mean diameter in LCF is smaller than for LF with a decrease from 524 $\mu \mathrm{m}$ to $290 \mu \mathrm{m}$. From these results, it can be inferred that the addition of biomass has a negative effect on the mechanical strength of the particles, making them more prone to fragmentation in the early stages of calcination presumably due to thermal stresses they experience. Nevertheless, the introduction of cement seems to have a positive effect in the biomass-templated particle with respect to fragmentation.

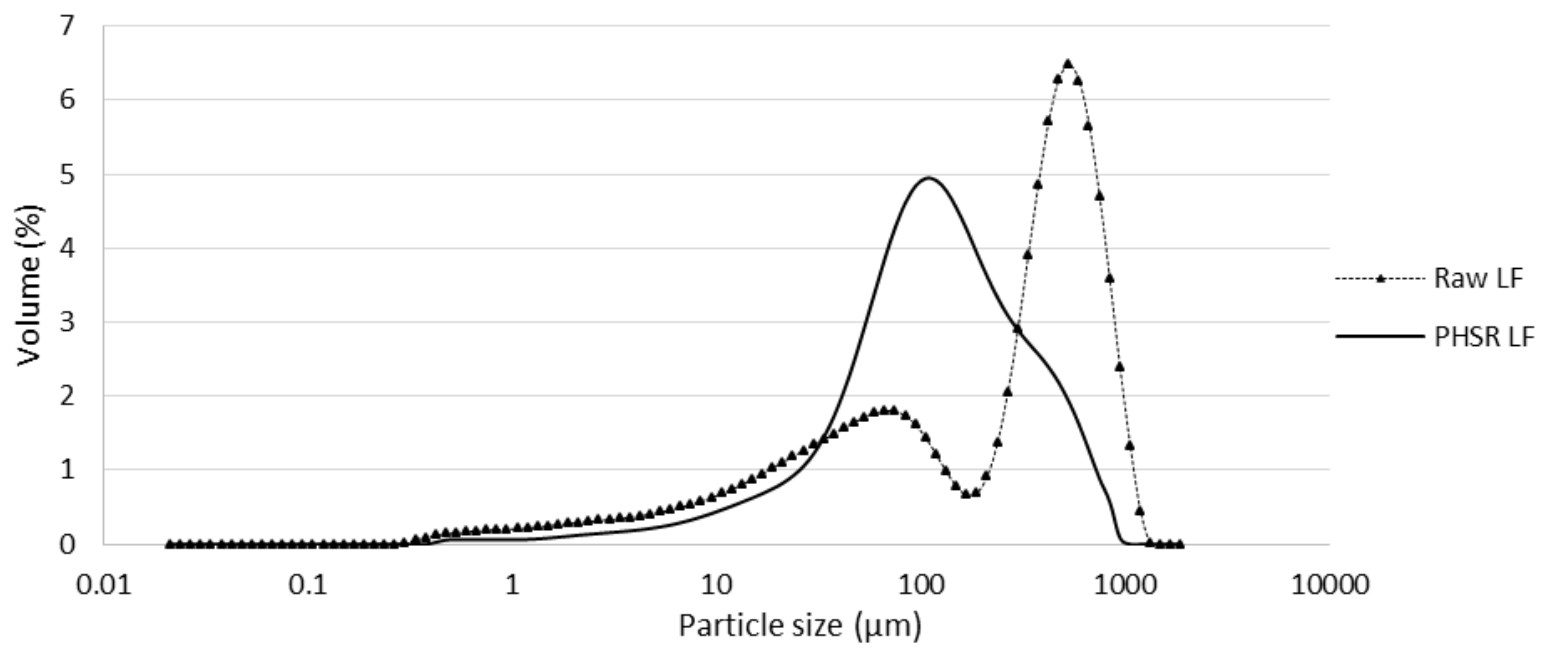

Figure 9: Particle size distribution of LF before and after the PHSR tests 


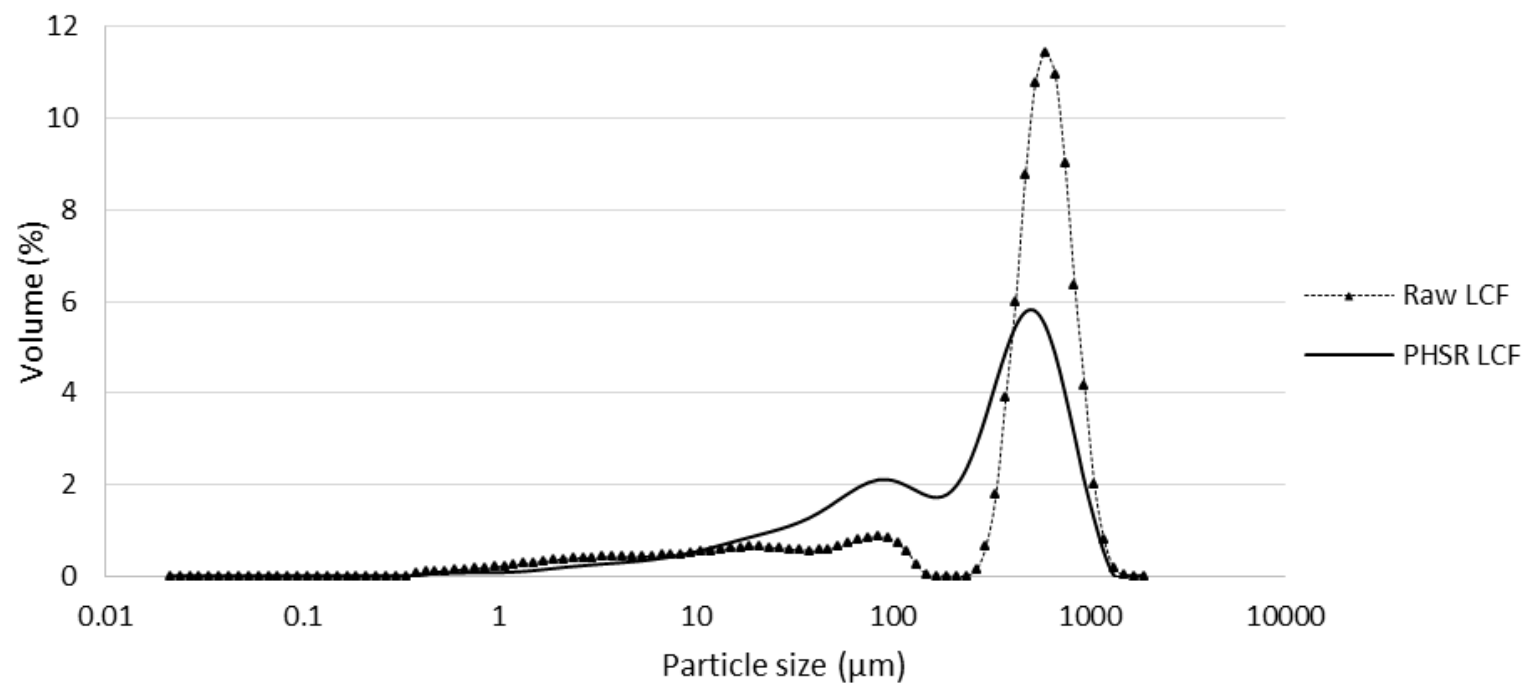

Figure 10: Particle size distribution of LCF before and after the PHSR tests

\subsubsection{BFB experiments}

218 Figures 11-14 report the results of fragmentation tests in the fluidised bed reactor.

Figure 11 reports the PSDs after treating the samples of LC, LF and LCF of original size 500-710 $\mu \mathrm{m}$ in the fluidised bed reactor in air. There is a clear difference in the behaviour among samples; LC undergoes less fragmentation, with $82 \%$ of the samples retaining the initial size range, as compared to LF, with $33 \%$ of the sample in the initial size range and LCF, with $47 \%$ of the sample in the initial size range. However, as noted in the PHSR experiments, cement addition has a positive effect making the particles less susceptible to fragmentation than the biomass-only templated material (LF).

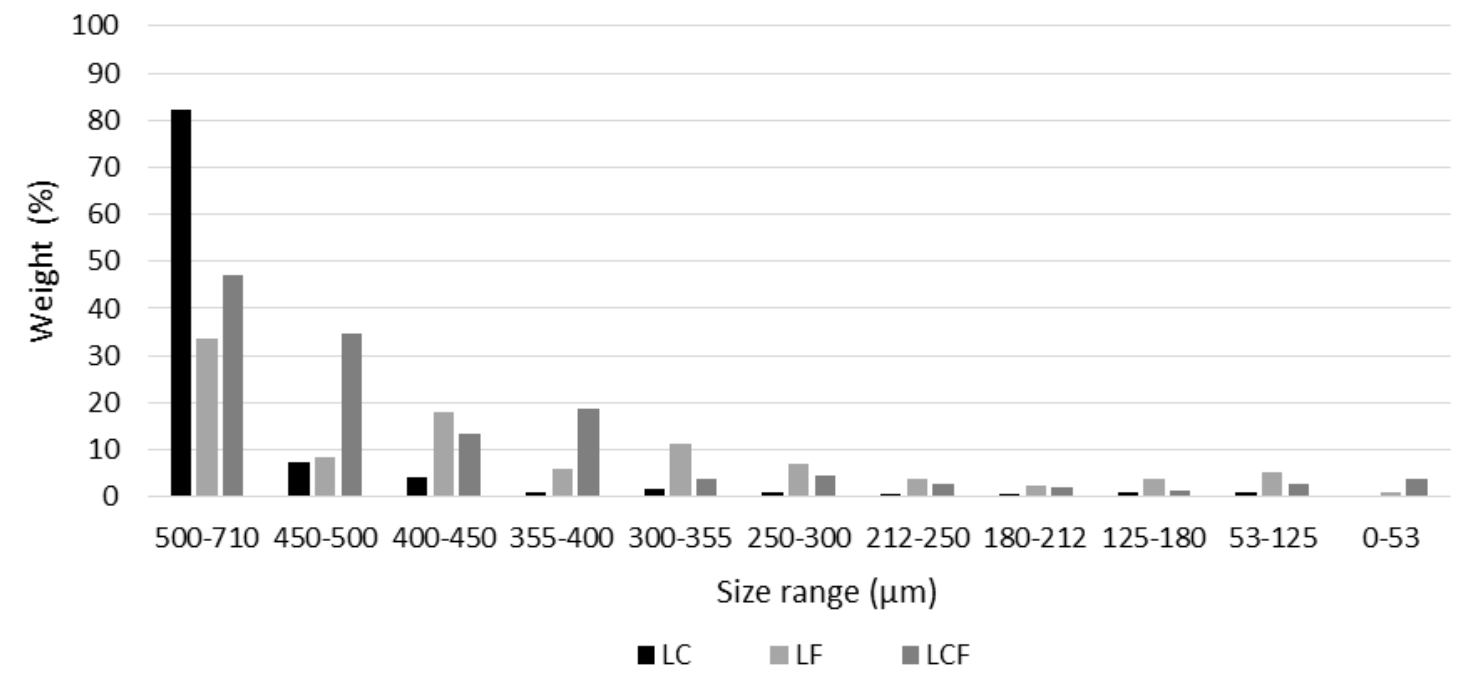

Figure 11: Weight distribution percentage of recovered material $\left(500-710 \mu \mathrm{m}, 900{ }^{\circ} \mathrm{C}\right.$ in air) 


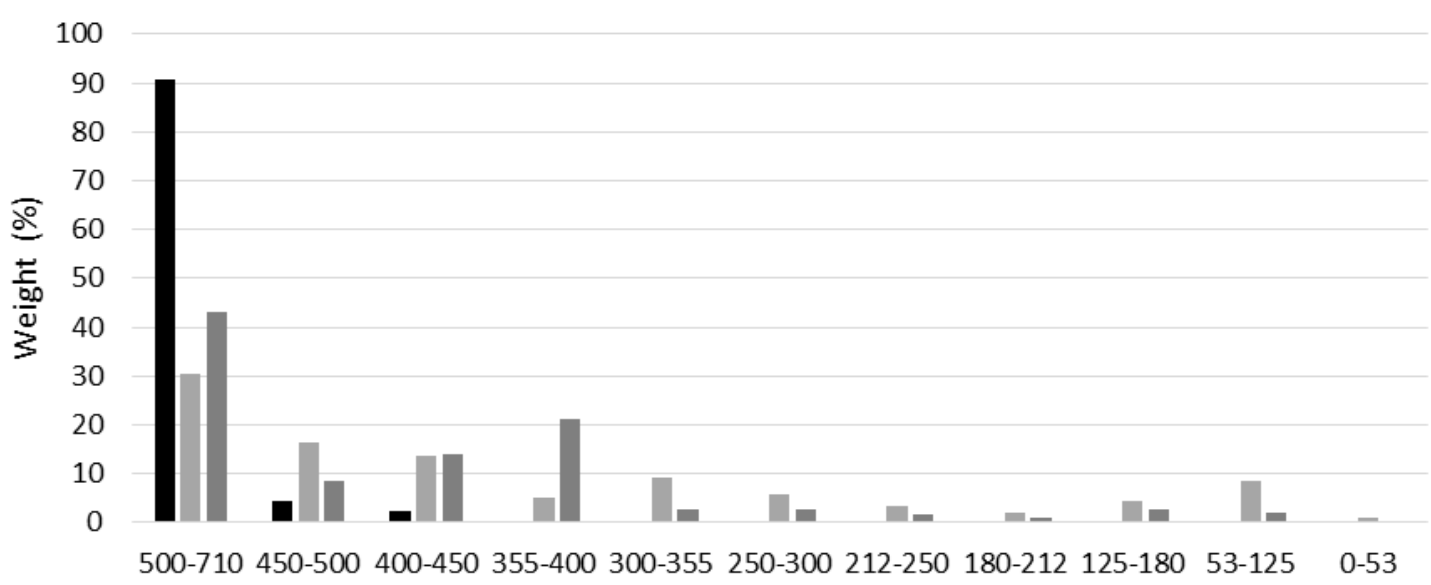

Size range $(\mu \mathrm{m})$

Figure 12: Weight distribution percentage of recovered material $\left(500-710 \mu \mathrm{m}, 900{ }^{\circ} \mathrm{C}\right.$ in $70 \%$ vol CO, $30 \%$ vol air)

Figure 12 reports the weight distribution of the material after calcination of the same samples in $70 \% \mathrm{CO}_{2}$ with balance of air. It can be seen that the material that fragments the most is LF with only $30 \%$ of the particles remaining in the initial size range, followed by LCF with $43 \%$ and LC with $90 \%$.

The results of the same tests carried out on samples of smaller particle size (250-500 $\mu \mathrm{m})$, are reported in Figures 13-14. For calcination in air, LF has the highest fragmentation with only $67 \%$ of particles retaining the initial size, followed by LCF with $74 \%$ and LC with $94 \%$. It can be seen that smaller particle sizes lead to less fragmention of the material recovered in the reactor at the end of the tests.

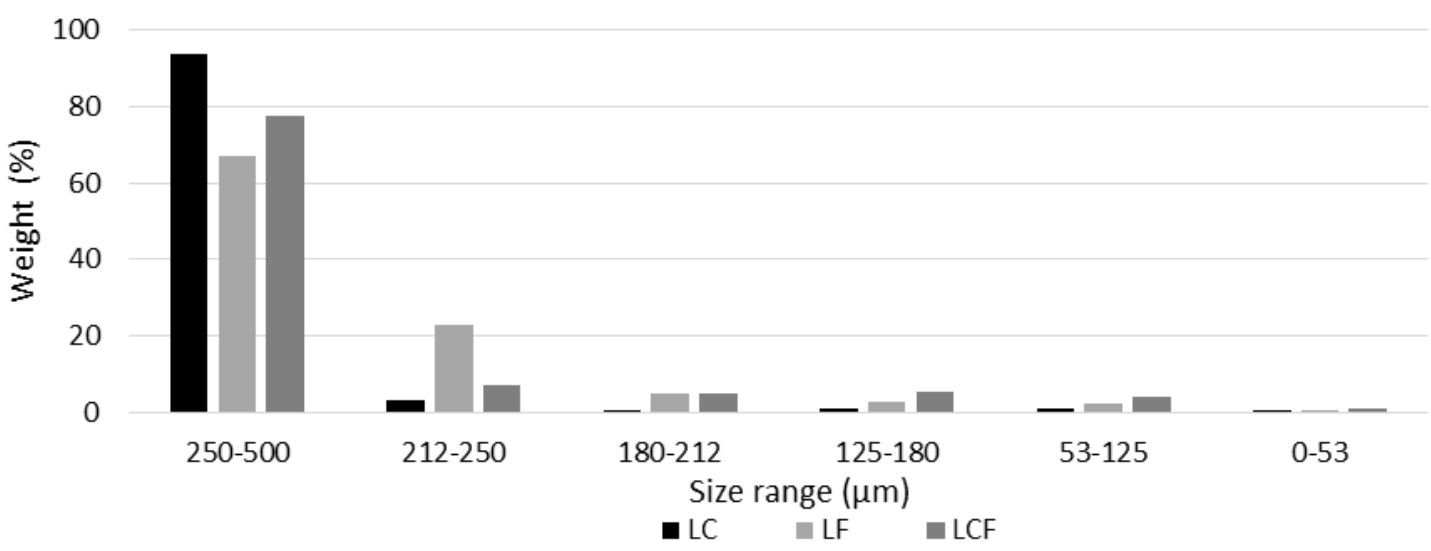

242 Figure 13: Weight distribution percentage of recovered material $\left(250-500 \mu \mathrm{m}, 900{ }^{\circ} \mathrm{C}\right.$ in air)

243 For the smaller size particles $(250-500 \mu \mathrm{m})$ calcined in $70 \% \mathrm{CO}_{2}$ with balance of air, the results were qualitatively similar to the other results. Nevertheless, the particles that remained in the reactor underwent less fragmentation than LF with $62 \%$ of particles in the initial size range, as was expected. The amount of fines (53-125 $\mu \mathrm{m}$ 
and $125-180 \mu \mathrm{m})$ is higher for LF $(0.9 \% w t)$ and LCF $(0.08 \% w t)$ and LC $(0.04 \% w t)$,

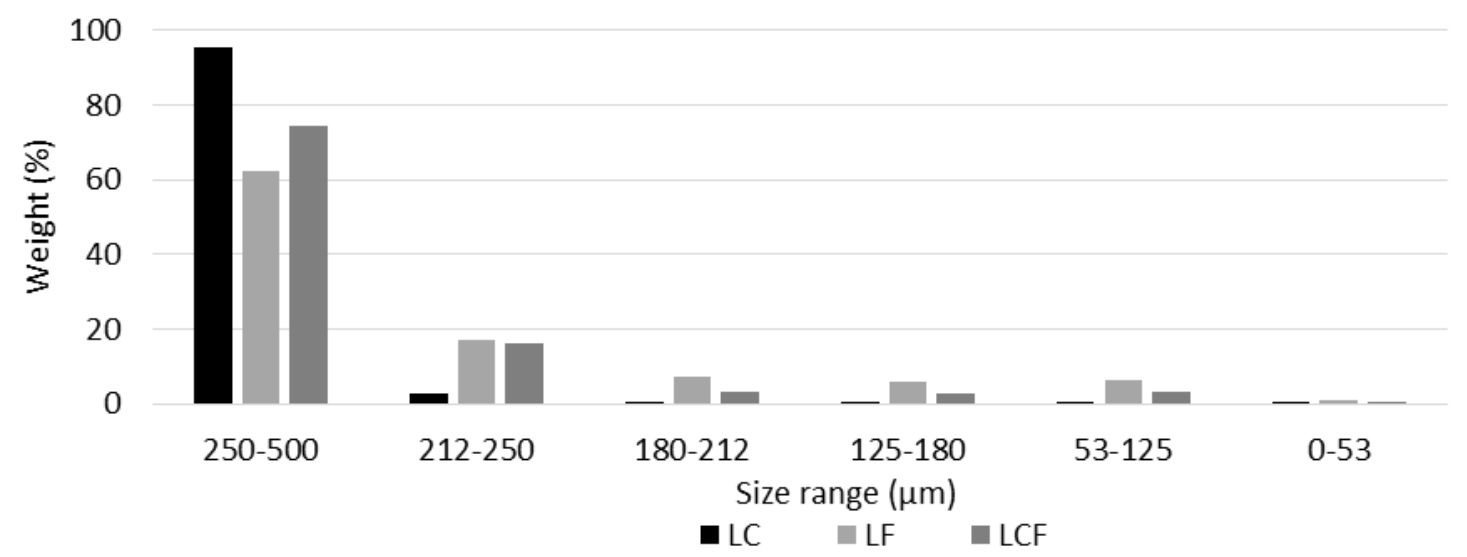

Figure 14: Weight distribution percentage of recovered material $\left(250-500 \mu \mathrm{m}, 900{ }^{\circ} \mathrm{C}\right.$ in $70 \%$ 251 vol $\mathrm{CO}_{2}, 30 \%$ vol air)

The percentage of material loss in the course of the BFB experiments is reported in Table 2. It can be seen that around $45 \%$ weight of LF was lost in the first calcination for smaller particles and around $30 \%$ for larger particles. This loss would be unacceptable for any real system. For LCF the losses were less significant for larger particles (between 4-8\%), whilst for the smaller particles LCF behaved very similar to LF. The material that performed best was LC with a loss of around $3 \%$ for the smaller sample and $30 \%$ for the larger sample. Interestingly, the gas composition used in the calcination process did not affect the results significantly.

It has been noted above that LCF and LF have similar behaviour for the smaller particle range; this could be due to the different composition in the larger LCF particles, which might incorporate more cement during the pelletisation process. This hypothesis was supported by comparing the results of pyrolysis-calcination TGA experiments carried out on LCF samples of different size cuts. The TG curves, reported in Figure 15 show a smaller water content for the larger particles which suggests that they contained more calcium aluminate cement than the smaller size range particles. However, it should be noted that the particle size effect observed in Table 2 could be related to elutriation. The contribution of elutriation to the loss of bed material is in fact more noticeable the smaller the particle size is. Another point worth reiterating is that the main difference between both size ranges is the amount of cement present in each size cut. The effect of adding cement has been extensively studied in previous papers. There is a negative impact of adding cement because the particles have less active $(\mathrm{CaO})$ material in them so that would negative influence there $\mathrm{CO}_{2}$ uptake, also cement reacts with lime to form mayenite $\left(\mathrm{Ca}_{12} \mathrm{Al}_{14} \mathrm{O}_{33}\right)$. However, a positive effect has also been found in which the addition of calcium aluminate cement stabilizes the structure of the particle due to a mesoporous $\mathrm{Al}_{2} \mathrm{O}_{3}$ phase that delays sintering and therefore decreases the reactivity decay over cycles $[26,44]$. 
Table 2: Loss in sample weight during the BFB experiments

\begin{tabular}{lllll}
\hline Sample & \multicolumn{2}{l}{$\begin{array}{l}\text { Loss of mass in weight (\%) for } \mathbf{1 0 0 \%} \\
\text { vol air }\end{array}$} & \multicolumn{2}{l}{$\begin{array}{l}\text { Loss of mass in weight (\%) for } \mathbf{7 0 \%} \\
\text { vol } \mathbf{C O}_{2} \text { and } \mathbf{3 0 \%} \text { vol air }\end{array}$} \\
& $\mathbf{2 5 0 - 5 0 0} \boldsymbol{\mu m}$ & $\mathbf{5 0 0 - 7 1 0} \boldsymbol{\mu m}$ & $\mathbf{2 5 0 - 5 0 0} \boldsymbol{\mu m}$ & $\mathbf{5 0 0 - 7 1 0} \boldsymbol{\mu m}$ \\
\hline LC & 31.3 & 3.3 & 29.3 & 3.7 \\
LF & 45.4 & 27.4 & 46.8 & 30.5 \\
LCF & 41.5 & 3.4 & 48.4 & 8.7 \\
\hline
\end{tabular}

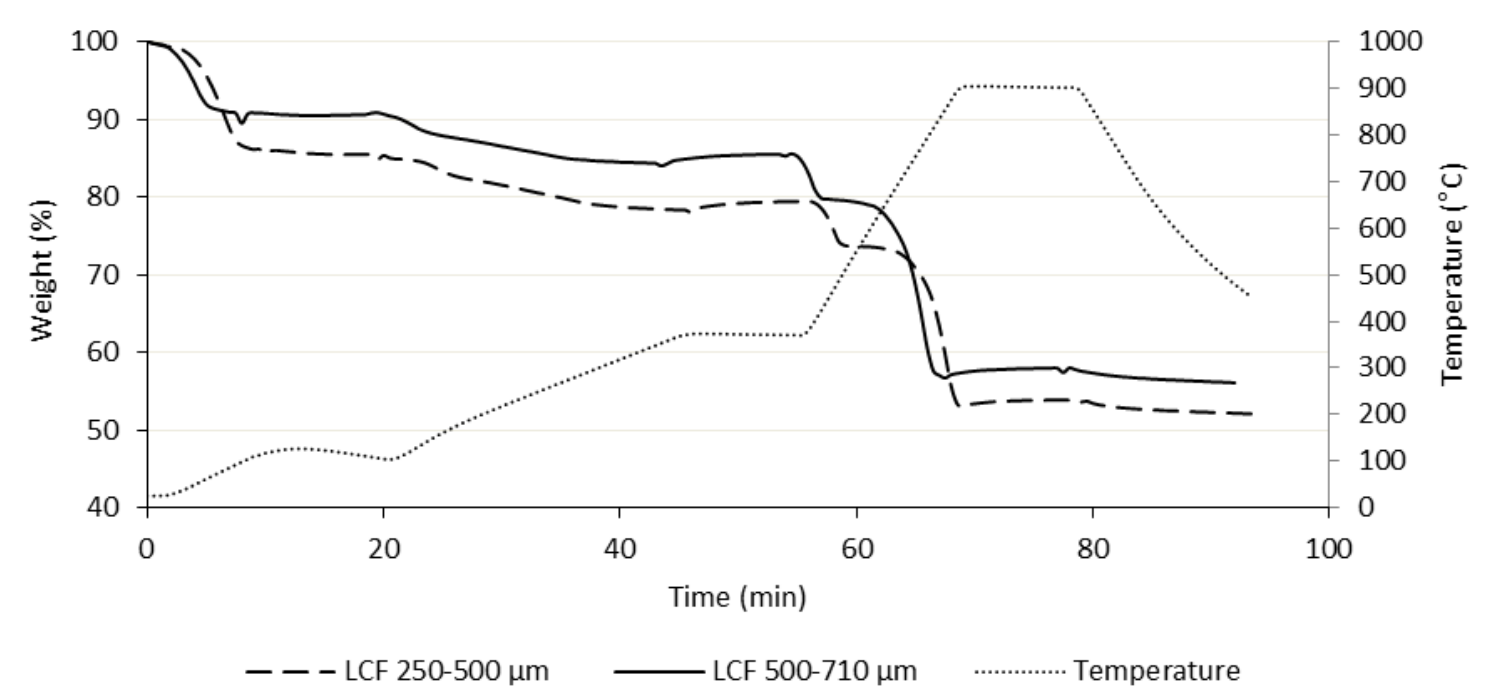

281 Figure 15: TG Results for LCF $(250-500 \mu \mathrm{m})$ and LCF $(500-710 \mu \mathrm{m})$ for the first calcination

\section{Conclusions}

Biomass-templated pellets for calcium looping appear to be a cheap and scalable alternative option to achieve high $\mathrm{CO}_{2}$ uptake when compared with other synthetic materials for $\mathrm{Ca}$ looping. The reactivity of these templated materials has been previously investigated in both TGA and BFB. Here, LF experienced the highest fragmentation in PHSR tests with a reduction in mean diameter of $404 \mu \mathrm{m}$ compared to $234 \mu \mathrm{m}$ for LCF and no change for LC. Moreover, in BFB, LF displayed the worst performance with a mass loss as high as $45.4 \%$ wt for smaller particles in the air fluidisation case. The weight loss of this material was significantly higher than for LC with $31.3 \%$ wt for the same case; this suggests that addition of biomass has a detrimental effect with regards to fragmentation. This effect is partially counteracted by the addition of calcium aluminate cement, which augments the resistance to fragmentation for LCF. However, the composition of LCF varied with particle size with the smaller range $(250-500 \mu \mathrm{m})$ showing more elutriation of fines due to the pelletisation process, in which the larger particle size appeared to have incorporated more cement, leaving the smaller particles with a less stable structure. In consequence, smaller LCF particles were more prone to elutriate than the larger ones $(500-710 \mu \mathrm{m})$. However, the particles that stayed in the reactor for the duration of the test underwent less fragmentation compared to the larger size range. It is clear that LC is the best material as regards fragmentation in all the cases explored, with a loss in mass as low as $3.3 \%$ for $500-710 \mu \mathrm{m}$ particles in air calcination. The results for both techniques, BFB and PHSR, agree on the effects that biomass-templating 
has on the fragmentation behaviour of these sorbents under calcium looping conditions, although the addition of cement partially mitigated this negative effect.

\section{Acknowledgments}

The authors wish to thank Professor Fabio Montagnaro, Dr Massimo Urciuolo and Mr Luciano Cortese for their support and advice during this investigation. The research leading to these results has received funding from the European Community's Research Fund for Coal and Steel (RFCS) under grant agreement $n^{\circ}$ RFCR-CT2012-00008. The authors would also like to acknowledge the financial support of the UK CCS Research Centre (www.ukccsrc.ac.uk) in carrying out this work. The UKCCSRC is funded by the EPSRC as part of the RCUK Energy Programme. In addition, the authors wish to thank Almantis Inc. and Longcliffe UK for providing the materials used in this work.

\section{References}

[1] Stanmore BR, Gilot P. Review - calcination and carbonation of limestone during thermal cycling for $\mathrm{CO}_{2}$ sequestration. Fuel Process Technol 2005;86:1707-1743.

[2] Alonso M, Rodríguez N, González B, Grasa G, Murillo R, Abanades JC. Carbon dioxide capture from combustion flue gases with a calcium oxide chemical loop. Int $\mathrm{J}$ Greenhouse Gas Control 2010;4:167-173.

[3] Blamey J, Anthony EJ, Fang J, Fennell PS. The calcium looping cycle for largescale $\mathrm{CO}_{2}$ capture. Prog Energy Combust Sci 2010;36:260-279.

[4] Sun R, Li Y, Liu H, Wu S, Lu C. $\mathrm{CO}_{2}$ capture performance of calcium-based sorbent doped with manganese salts during calcium looping cycle. Appl Energy 2012;89(1):368-373.

[5] Lysikov $\mathrm{Al}$, Salanov AN, Okunev AG. Change of $\mathrm{CO}_{2}$ carrying capacity of $\mathrm{CaO}$ in isothermal recarbonation-decomposition cycles. Ind Eng Chem Res 2007;46:46334638.

[6] Abanades JC, The maximum capture efficiency of $\mathrm{CO}_{2}$ using a carbonation/ calcination cycle of $\mathrm{CaO} / \mathrm{CaCO}_{3}$. Chem Eng J 2002;90:303-306.

[7] Blamey J, Paterson NPM, Dugwell DR, Fennell PS, Mechanism of particle breakage during reactivation of $\mathrm{CaO}$-based sorbents for $\mathrm{CO}_{2}$ capture. Energy \& Fuels 2010;24:4605-4616.

[8] Rodríguez N, Alonso M, Abanades JC, Average activity of $\mathrm{CaO}$ particles in a calcium looping system. Chem Eng J 2010;156:388-394.

[9] Grasa GS, Abanades JC. $\mathrm{CO}_{2}$ capture capacity of $\mathrm{CaO}$ in long series of carbonation/calcination cycles. Ind Eng Chem Res 2006;45:8846-8851. 
[10] Lisbona P, Martínez A, Romeo LM. Hydrodynamical model and experimental results of a calcium looping cycle for $\mathrm{CO}_{2}$ capture. Appl Energy 2013;101:317-322.

[11] Chen S, Xiang W, Wang D, Xue Z. Incorporating IGCC and CaO sorptionenhanced process for power generation with $\mathrm{CO}_{2}$ capture. Appl Energy 2012;95:285-294.

[12] Lasheras A, Ströhle J, Galloy A, Epple B. Carbonate looping process simulation using a 1D fluidized bed model for the carbonator. Int J Greenh Gas Control 2011;5: 686-693.

[13] Dean CC, Blamey J, Florin NH, Al-Jeboori MJ, Fennell PS. The calcium looping cycle for $\mathrm{CO}_{2}$ capture from power generation, cement manufacture and hydrogen production. Chem Eng Res Des 2011;89:836-855.

[14] Luo C, Zheng $\mathrm{Y}$, Ding N, Wu Q, Bian G, Zheng D. Development and performance of $\mathrm{CaO} / \mathrm{La}_{2} \mathrm{O}_{3}$ sorbents during calcium looping cycles for $\mathrm{CO}_{2}$ capture. Ind Eng Chem.Res 2010;49: 11778-17784.

[15] Luo C, Zheng Y, Zheng C, Yin J, Qin C, Feng B. Manufacture of calcium-based sorbents for high temperature cyclic $\mathrm{CO}_{2}$ capture via a sol-gel process. Int $\mathrm{J}$ Greenh Gas Control 2013;12: 193-199.

[16] Radfarnia HR, Sayari A. A highly efficient $\mathrm{CaO}$-based $\mathrm{CO}_{2}$ sorbent prepared by a citrate-assisted sol-gel technique. Chem Eng J 2015;262: 913-920.

[17] Wang B, Yan R, Lee DH, Zheng Y, Zhao H, Zheng C. Characterization and evaluation of $\mathrm{Fe}_{2} \mathrm{O}_{3} / \mathrm{Al}_{2} \mathrm{O}_{3}$ oxygen carrier prepared by sol-gel combustion synthesis. J Anal Appl Pyrolysis 2011;91: 105-113.

[18] Broda M, Müller CR. Sol-gel-derived, CaO-based, $\mathrm{ZrO}_{2}$-stabilized $\mathrm{CO}_{2}$ sorbents. Fuel 2014;127: 94-100.

[19] Zhang M, Peng Y, Sun Y, Li P, Yu J. Preparation of $\mathrm{CaO}-\mathrm{Al}_{2} \mathrm{O}_{3}$ sorbent and $\mathrm{CO}_{2}$ capture performance at high temperature. Fuel 2013;111: 636-642.

[20] Li Y, Su M, Xie X, Wu S, Liu C. CO2 capture performance of synthetic sorbent prepared from carbide slag and aluminum nitrate hydrate by combustion synthesis. Appl Energy 2015;145: 60-68.

[21] Li CC, Wu UT, Lin HP. Cyclic performance of $\mathrm{CaCO}_{3} \cdot \mathrm{mSiO}_{2}$ for $\mathrm{CO}_{2}$ capture in a calcium looping cycle. J Mater Chem A 2014;2: 8252-8257.

370 [22] Li L, King DL, Nie Z, Howard C. Magnesia-stabilized calcium oxide absorbents

\section{9;48: 10604-10613.}


[23] Zhao M, Bilton M, Brown AP, Cunliffe AM, Dvininov E, Dupont V, Comyn TP, Milne SJ. Durability of $\mathrm{CaO}-\mathrm{CaZrO}_{3}$ sorbents for high-temperature $\mathrm{CO}_{2}$ capture prepared by a wet chemical method. Energy \& Fuels 2014;28: 1275-1283.

[24] Gupta H, Fan LS. Carbonation-calcination cycle using high reactivity calcium oxide for carbon dioxide separation from flue gas. Ind Eng Chem Res 2002;41: 4035-4042.

[25] Florin N, Fennell PS. Synthetic CaO-based sorbent for $\mathrm{CO}_{2}$ capture. Energy Procedia 2011;4: 830-838.

[26] Manovic V, Anthony EJ. Screening of binders for pelletization of CaO-based sorbents for $\mathrm{CO}_{2}$ capture. Energy \& Fuels 2009;23: 4797-4804.

[27] Wu Y, Manovic V, He I, Anthony EJ. Modified lime-based pellet sorbents for high-temperature $\mathrm{CO}_{2}$ capture: Reactivity and attrition behaviour. Fuel 2012;96: 454461.

[28] Ridha FN, Manovic V, Macchi A, Anthony EJ. High-temperature $\mathrm{CO}_{2}$ capture cycles for $\mathrm{CaO}$-based pellets with kaolin-based binders. Int J Greenh Gas Control 2012;6: 164-170.

[29] Qin C, Yin J, An H, Liu W, Feng B. Performance of extruded particles from calcium hydroxide and cement for $\mathrm{CO}_{2}$ capture. Energy \& Fuels 2012;26: 154-161.

[30] Ridha FN, Wu Y, Manovic V, Macchi A, Anthony EJ. Enhanced $\mathrm{CO}_{2}$ capture by biomass-templated $\mathrm{Ca}(\mathrm{OH})_{2}$-based pellets. Chem Eng J 2015;274: 69-75.

[31] Manovic V, Anthony EJ. CaO-based pellets with oxygen carriers and catalysts. Energy \& Fuels 2011;25: 4846-4853.

[32] Erans M, Beisheim T, Manovic V, Jeremias M, Patchigolla K, Dieter H, Duan L, Anthony EJ. Effect of $\mathrm{SO}_{2}$ and steam on $\mathrm{CO}_{2}$ capture performance of biomasstemplated calcium aluminate pellets. Faraday Discuss 2016 (Accepted Manuscript). doi:10.1039/C6FD00027D.

[33] Scala F, Cammarota A, Chirone R, Salatino P. Comminution of limestone during batch fluidized-bed calcination and sulfation. AIChE J 1997;43: 363- 373.

[34] Scala F, Salatino P, Boerefijn R, Ghadiri M. Attrition of sorbents during fluidized bed calcination and sulphation. Powder Technol 2000;107: 153- 167.

[35] Scala F, Salatino P. Dolomite attrition during fluidized-bed calcination and sulfation. Combust Sci Technol 2003:175: 2201-2216.

[36] Scala F, Montagnaro F, Salatino P. Attrition of limestone by impact loading in fluidized beds. Energy \& Fuels 2007;21: 2566-2572. 
[37] Coppola A, Scala F, Salatino P, Montagnaro F. Fluidized bed calcium looping cycles for $\mathrm{CO}_{2}$ capture under oxy-firing calcination conditions: Part 1. Assessment of six limestones. Chem Eng J 2013;231:537-543. doi:10.1016/j.cej.2013.07.113.

[38] Coppola A, Montagnaro F, Salatino P, Scala F. Attrition of limestone during fluidized bed calcium looping cycles for $\mathrm{CO}_{2}$ capture. Combust Sci Technol 2012;184: 929-941.

[39] Coppola A, Montagnaro F, Salatino P, Scala F. Fluidized bed calcium looping: the effect of $\mathrm{SO}_{2}$ on sorbent attrition and $\mathrm{CO}_{2}$ capture capacity. Chem Eng J 2012; 207-208: 445-449.

[40] Senneca O, Cortese L. Thermal annealing of coal at high temperature and high pressure. Effects on fragmentation and on rate of combustion, gasification and oxycombustion. Fuel 2014;116: 221-228.

[41] Fennell PS, Pacciani R, Dennis JS, Davidson JF, Hayhurst AN. The effects of repeated cycles of calcination and carbonation on a variety of different limestones, as measured in a hot fluidized bed of sand. Energy \& Fuels 2007;21(4): 2072-2081.

[42] González B, Alonso M, Abanades JC. Sorbent attrition in a carbonation/calcination pilot plant for capturing $\mathrm{CO}_{2}$ from flue gases. Fuel 2010;89(10): 2918-2924.

[43] Manovic V, Anthony EJ. CaO-based pellets supported by calcium aluminate cements for high-temperature $\mathrm{CO}_{2}$ capture. Environ Sci Technol 2009;43: 71177122.

[44] Manovic V, Anthony EJ. Long-term behavior of CaO-based pellets supported by calcium aluminate cements in a long series of $\mathrm{CO}_{2}$ capture cycles. Ind Eng Chem Res 2009;48(19): 8906-8912.

[45] Manovic V, Anthony EJ. Reactivation and remaking of calcium aluminate pellets for $\mathrm{CO}_{2}$ capture. Fuel 2011;90: 233-239.

Published by Elsevier. This is the Author Accepted Manuscript issued with:

Creative Commons Attribution Non-Commercial No Derivatives License (CC:BY:NC:ND 3.0).

The final published version (version of record) is available online at 10.1016/j.fuel.2016.09.061. Please refer to any applicable publisher terms of use. 